\title{
Converting a paper proforma template to a user friendly electronic database to collect traumatic brain injury data
}

\author{
M. Veera Prasad', Amit Agrawal' ${ }^{2}$, S. Satish Kumar ${ }^{3}$, \\ B.V. Subrahmanyan ${ }^{4}$, G. Malleswara Rao $^{2}$ \\ Narayna Medical College Hospital, Chinthareddypalem, Nellore, Andhra Pradesh (India) \\ ${ }^{1}$ Department of Hospital Administration \\ ${ }^{2}$ Professor of Neurosurgery, Department of Neurosurgery \\ ${ }^{3}$ Associate Professor of Emergency Medicine, Department of Emergency Medicine \\ ${ }^{4}$ Professor of Forensic Medicine, Department of Forensic Medicine
}

\begin{abstract}
A structured reporting system which is based on a uniform template will permit uniform data collection and future statistics and will facilitate and validate independent or comparative audit of performance and quality of care. The successful establishment of a multi-center registry depends on the development of a concise data entry form, data entry system and data analysis to continuously maintain the registry. In the first phase we introduced the paper data collection form, in second phase this data form was converted to an electronic interface. In this second phase of the study the paper proforma which was developed in the first phase was converted into an electronic database by using the FileMaker Pro 13 Advanced $^{\oplus}$. The FileMaker Pro 13 Advanced $^{\circledR}$ is capable to store the data, provides user friendly interface to enter data and can be converted the standalone runtime program to install in any other computer system. The next step is to explore the possibility whether it would be feasible to use this as a multicenter traumatic brain injury registry.
\end{abstract}

Key words: registry, trauma, head injury, traumatic brain injury, FileMaker Pro 13 Advanced ${ }^{\circledR}$.

\section{Introduction}

The successful establishment of a multicenter trauma registry depends on the development of a concise data entry form, data entry system and data analysis to continuously maintain the registry. (1) The use of the common trauma template has been shown feasible across international registries for the majority of the data variables. (2) Based on the recommendation we have selected different data variables and we are making continuous efforts to identify the core variables versus optional data which can easily be used across many centers without compromising the quality of data. (3-5) In present article we describe our ongoing experience to convert an 
existing paper based data collection system into an electronic form based data collection interface.

\section{Material and methods}

The present study was conducted in the Departments of Hospital Administration, Neurosurgery and Department of Accident and Emergency Medicine of the Narayana Medical College and Hospital (NMCH) in Nellore, India. After approval from the institutional ethical committee, all patients with the diagnosis of traumatic brain injury (as per the criteria laid by International Classification of Disease injury codes ICD 10) presenting to the Departments of Neurosurgery and Emergency Medicine were included in the study. (6) It was the second phase of the ongoing project where core variables which were identified in the phase I were converted into an electronic database to maintain the uniformity and reproducibility. (7) In this second phase of the study the paper proforma which was developed in the first phase was converted into an electronic database by using the FileMaker Pro 13 Advanced $^{\circ}$. The FileMaker Pro 13 Advanced $^{\circ}$ is capable to store the data, provides user friendly interface to enter data and can be converted the standalone runtime program to install in any other computer system. Variables were identified as per the international norms and the data points were selected which included demographic details, pre-hospital characteristics, clinical details in emergency room, injury details, course during hospital stay, treatment, diagnosis, disposition and follow up. (8-10) Glasgow Coma Scale score was used to classify severity of the traumatic brain injury (11) and acute injury severity scoring (AIS) was used to grade the severity of the injury. (12) Additional grading systems were used to classify the severity of diffuse axonal injury (13) and subarachnoid hemorrhage on CT scan. $(14,15)$ Glasgow Outcome Scale (GOS) will be used to assess the follow up and outcome. (16)

\section{Statistical analysis}

Data were presented as the mean and standard deviation for continuous variables and as a percentage for categorical variables. Statistics were calculated using PSPP Statistical Software. (17)

\section{Results}

Paper proforma (Annexure I) which was used for data collection able to collect the patient information, clinical details, injury details, details regarding pre-hospital care, emergency room data, investigation detail (including details of CT scan), management offered, immediate outcome and details of short as well as long term follow up. Electronic counterpart which was developed by using the FileMaker Pro 13 Advanced $^{\oplus}$ replicated all these details and had all the variables which were included on the paper proforma. All the variables were stored in a single table in the background. This similarity provided an opportunity to uniformly display the contents and ease of data entry. To facilitate data entry, data were separated into sub groups by tabs which included patient demographics, injury details, emergency evaluation, treatment, inhospital course, discharge details, diagnosis and follow up. The collected data can be exported into spreadsheet for further analysis by any statistical software program. Interim 
DOI: 10.2478/romneu-2014-0059

analysis revealed that we were able to capture data for age, gender, education, brought by, date of admission, loss of consciousness, vomiting, nausea, ear bleed, nasal bleed, oral bleed, headache and seizures in all 100\% instances (Table 1). The most useful features of the program were similarity between paper and electronic interface (means easy to capture data and easy to enter data feature) (Figure 1) and ability to export data in a format which can be easily utilized for data analysis.

\section{Discussion}

Many of the data registries are guided through the American College of Surgeons guidelines for selection of data points. $(18,19)$ The amount of information captured may vary from a "minimal dataset" collected in emergency departments to a "comprehensive dataset" with information encompassing from pre-hospital care, management, follow up to rehabilitation. (19-22) The paucity of data, incomplete understanding of the problem and non-availability of definitive guidelines is a challenge to answer many important clinical questions and questions related to the management of traumatic brain injuries. (23) Data collection particularly a registry database is considered indispensable (at the same time it must be as inexpensive as possible). (24) In our previous studies we have found that a welldesigned Proforma based under supervision data collection in a relatively low volume trauma center and at regular intervals can be cost- effective which can be managed by personnel with basic training. $(7,25-29)$

\section{TABLE I}

Completeness of data details in the ongoing for the selected variables

\begin{tabular}{|l|l|l|}
\hline Data variable & Total & Percent \\
\hline Age & 311 & $100 \%$ \\
\hline Gender & 311 & $100 \%$ \\
\hline Education & 311 & $100 \%$ \\
\hline Brought by & 311 & $100 \%$ \\
\hline Date of Admission & 311 & $100 \%$ \\
\hline Loss of consciousness & 311 & $100 \%$ \\
\hline Vomiting & 311 & $100 \%$ \\
\hline Nausea & 311 & $100 \%$ \\
\hline Ear bleed & 311 & $100 \%$ \\
\hline Nasal bleed & 311 & $100 \%$ \\
\hline Oral bleed & 311 & $100 \%$ \\
\hline Headache & 311 & $100 \%$ \\
\hline Seizures & 311 & $100 \%$ \\
\hline Arrival Time In ED & 288 & $92.6 \%$ \\
\hline Left Time From ED & 285 & $91.6 \%$ \\
\hline Time of Admission & 283 & $91.0 \%$ \\
\hline Glasgow coma scale & 270 & $86.8 \%$ \\
\hline Best motor response & 270 & $86.8 \%$ \\
\hline Blood pressure systolic & 267 & $85.9 \%$ \\
\hline Blood pressure diastolic & 266 & $85.5 \%$ \\
\hline Best eye response & 262 & $84.2 \%$ \\
\hline Best verbal response & 262 & $84.2 \%$ \\
\hline Pulse rate & 260 & $83.6 \%$ \\
\hline Temperature & 206 & $66.2 \%$ \\
\hline Respiratory rate & 196 & $63.0 \%$ \\
\hline Hemoglobin & 91 & $29.3 \%$ \\
\hline Blood Sugar Random & 78 & $25.1 \%$ \\
\hline Date of Discharge & 70 & $22.5 \%$ \\
\hline Total leucocyte count & 68 & $21.9 \%$ \\
\hline Time of Injury & 67 & $21.5 \%$ \\
\hline Date of Injury & 58 & $18.6 \%$ \\
\hline & & \\
\hline
\end{tabular}




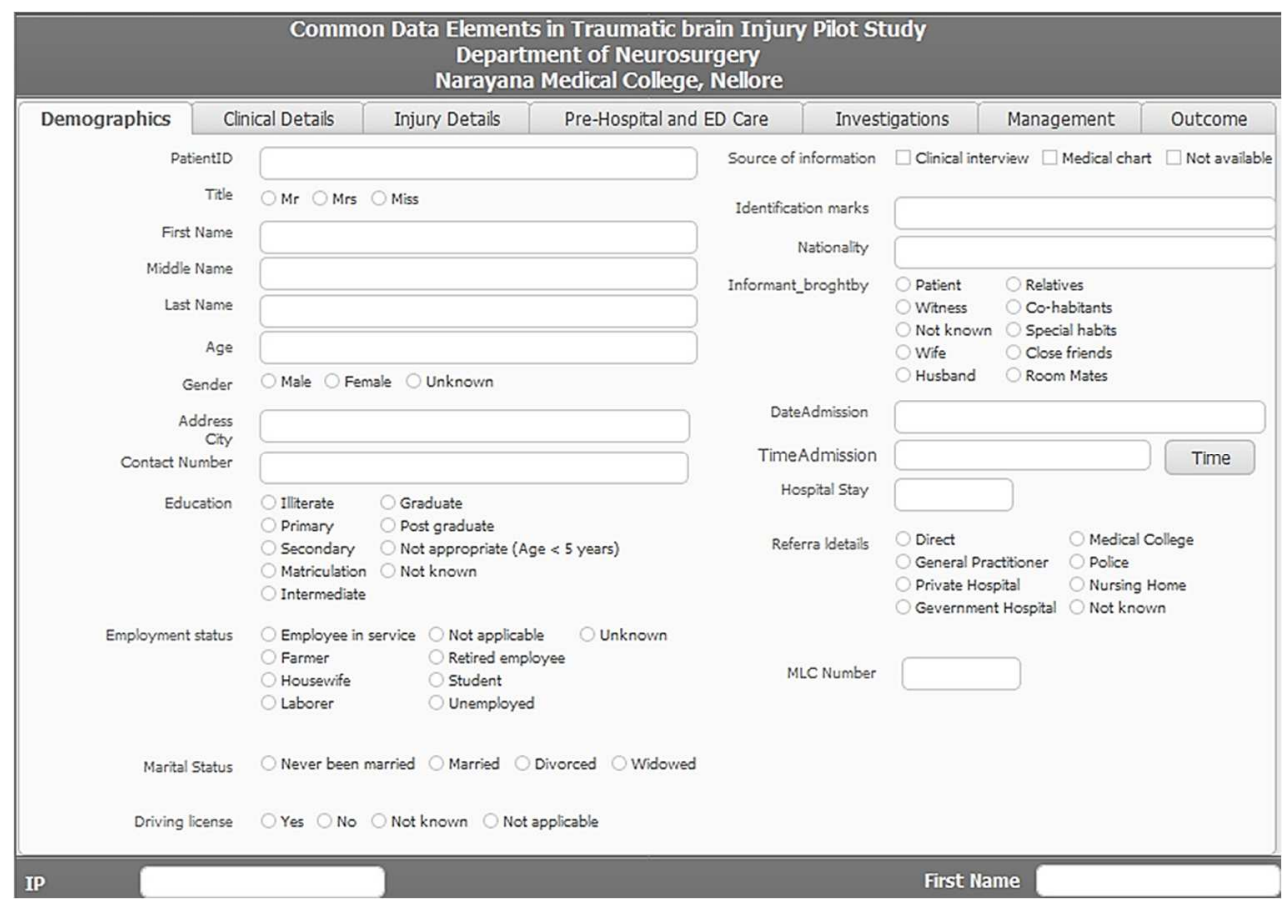

Figure 1 - Screenshot demonstrate that the exactly similar appearance between paper proforma and screen appearance

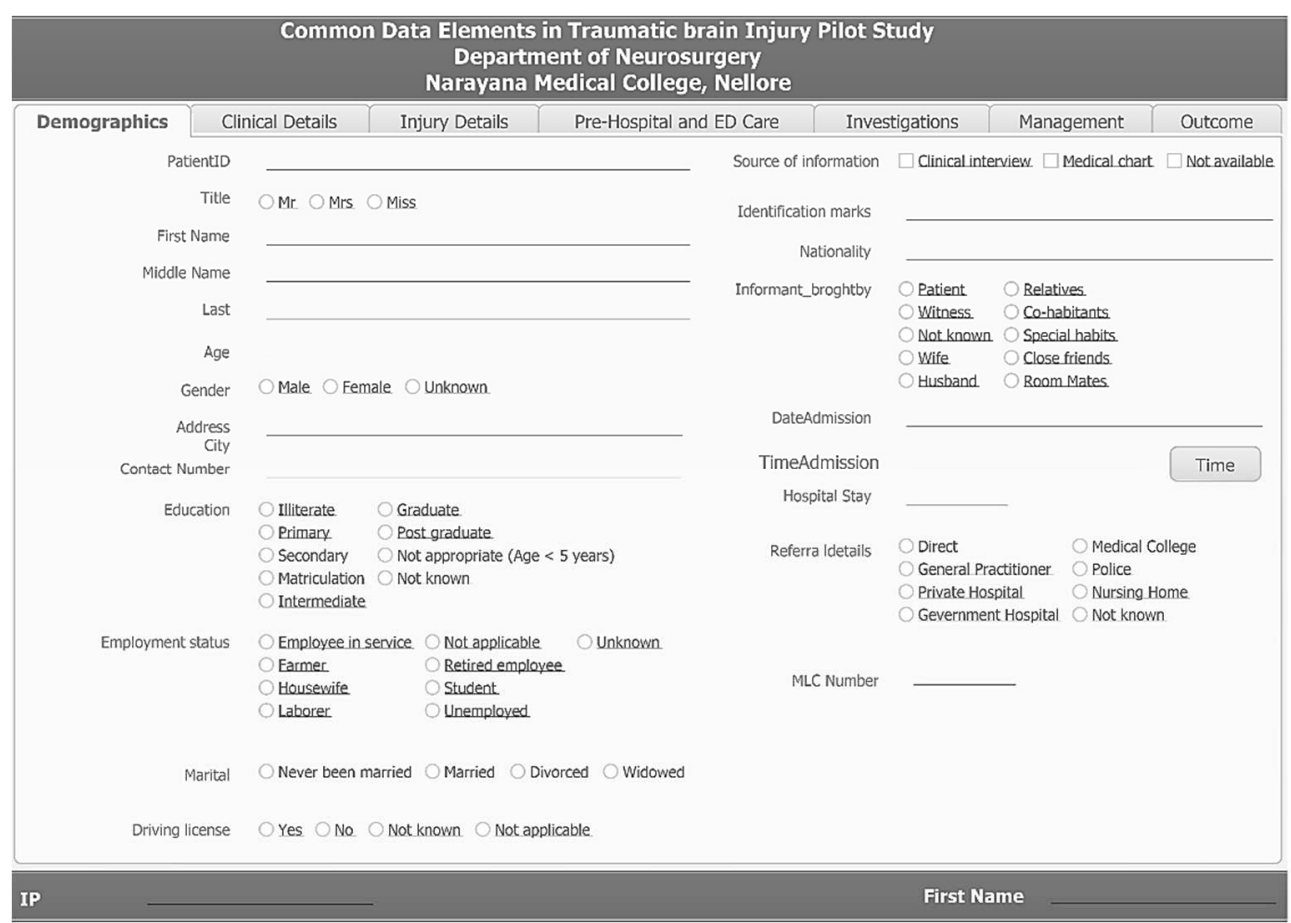


DOI: 10.2478/romneu-2014-0059

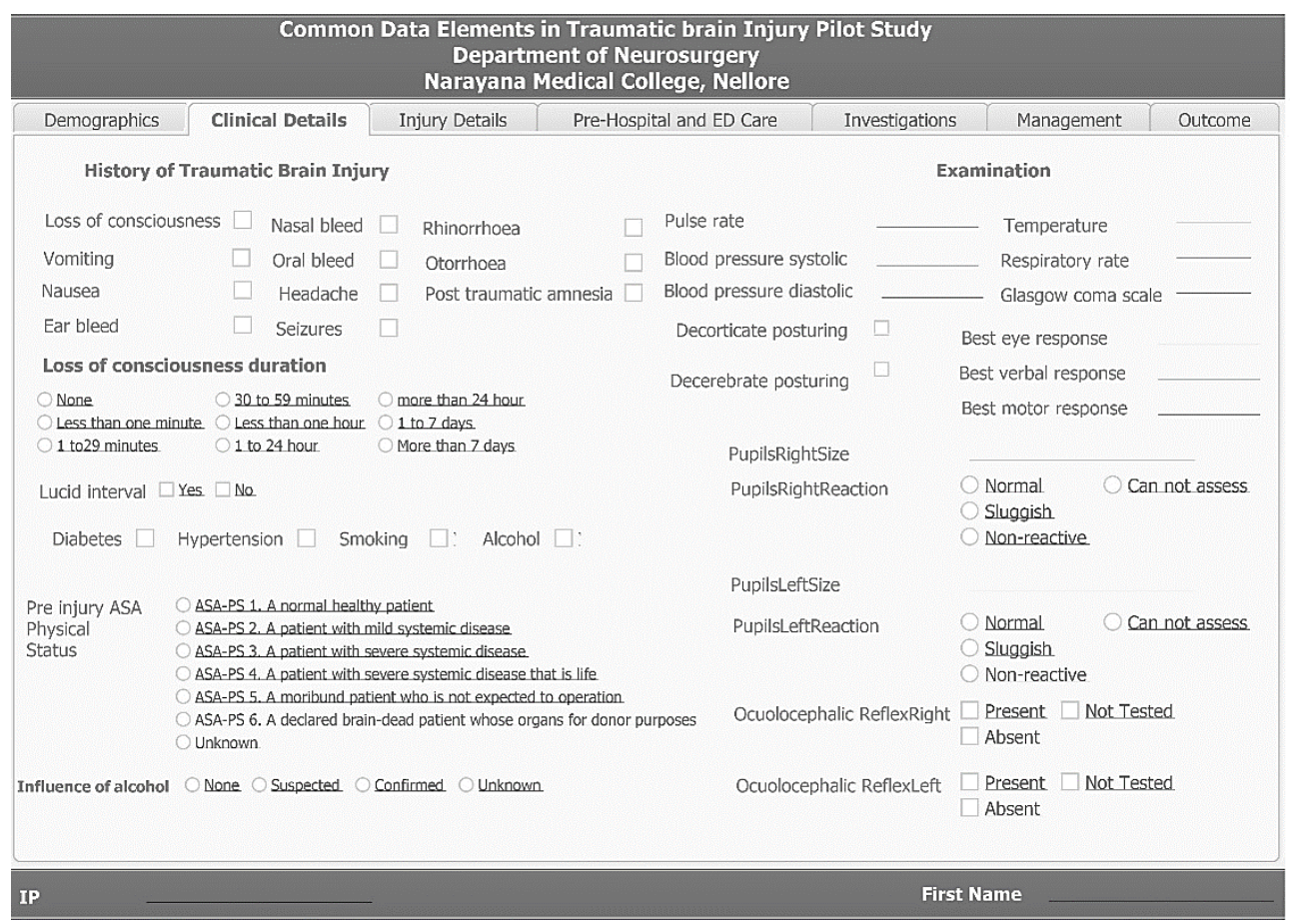

Common Data Elements in Traumatic brain Injury Pilot Study
Department of Neurosurgery
Narayana Medical College, Nellore




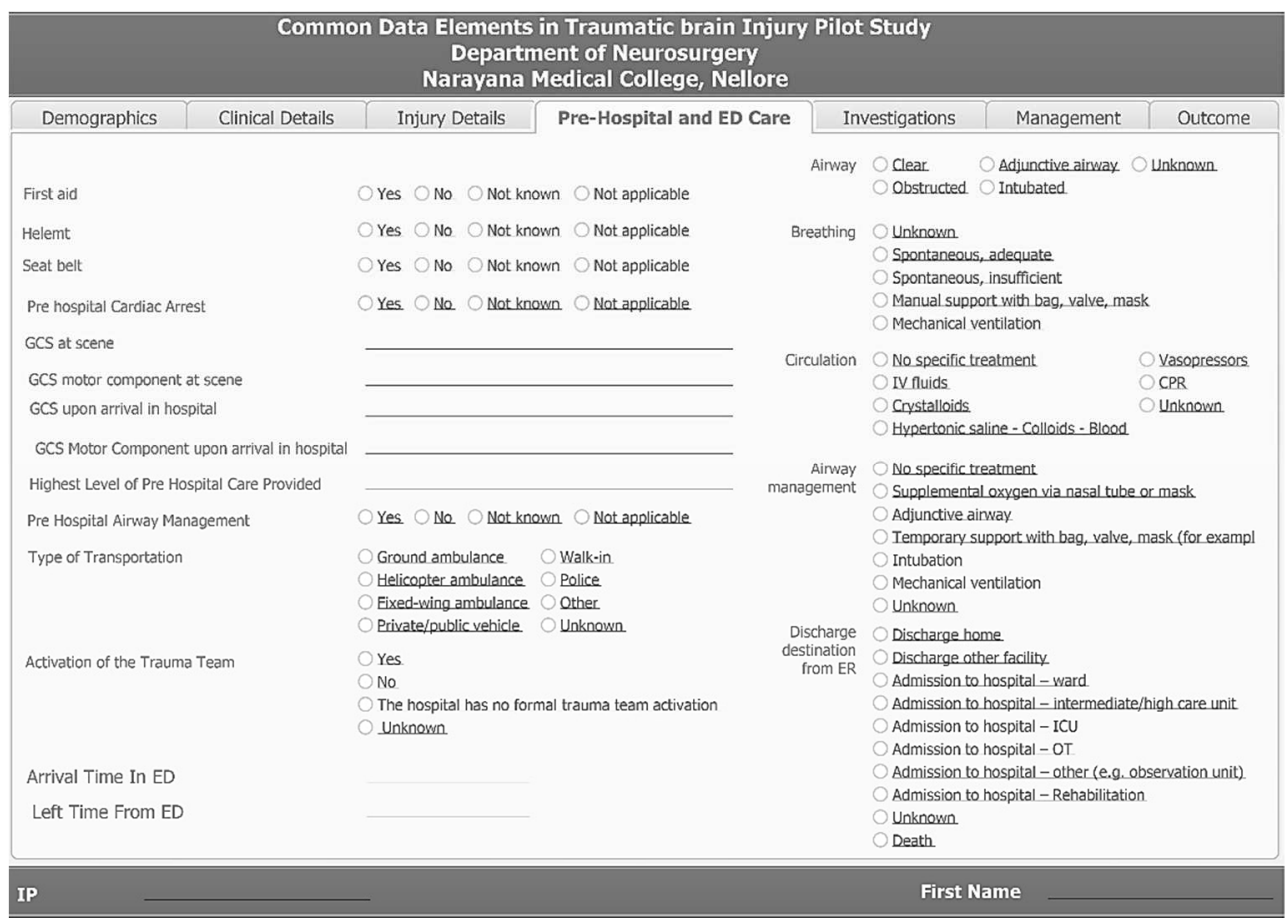

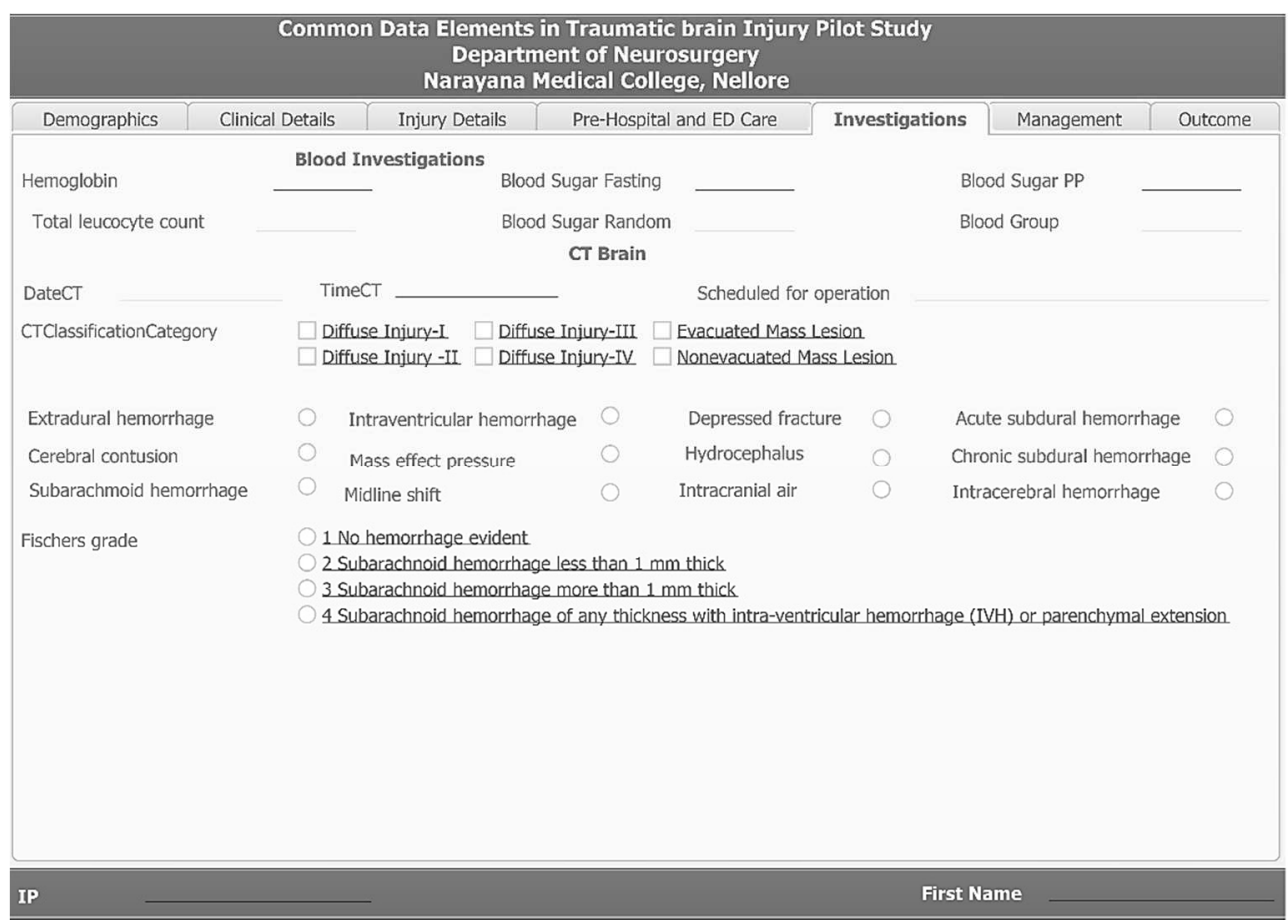


DOI: 10.2478/romneu-2014-0059

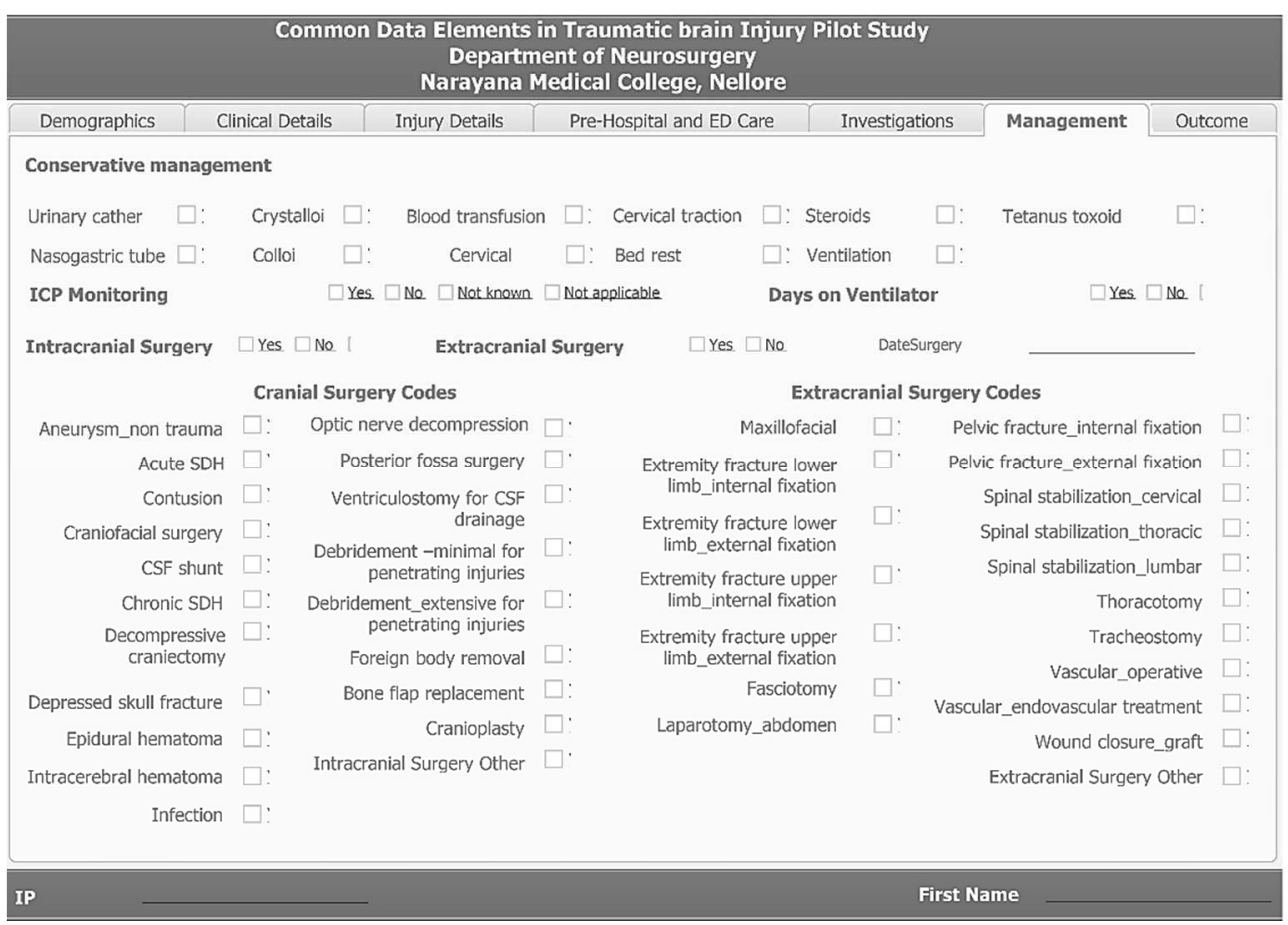

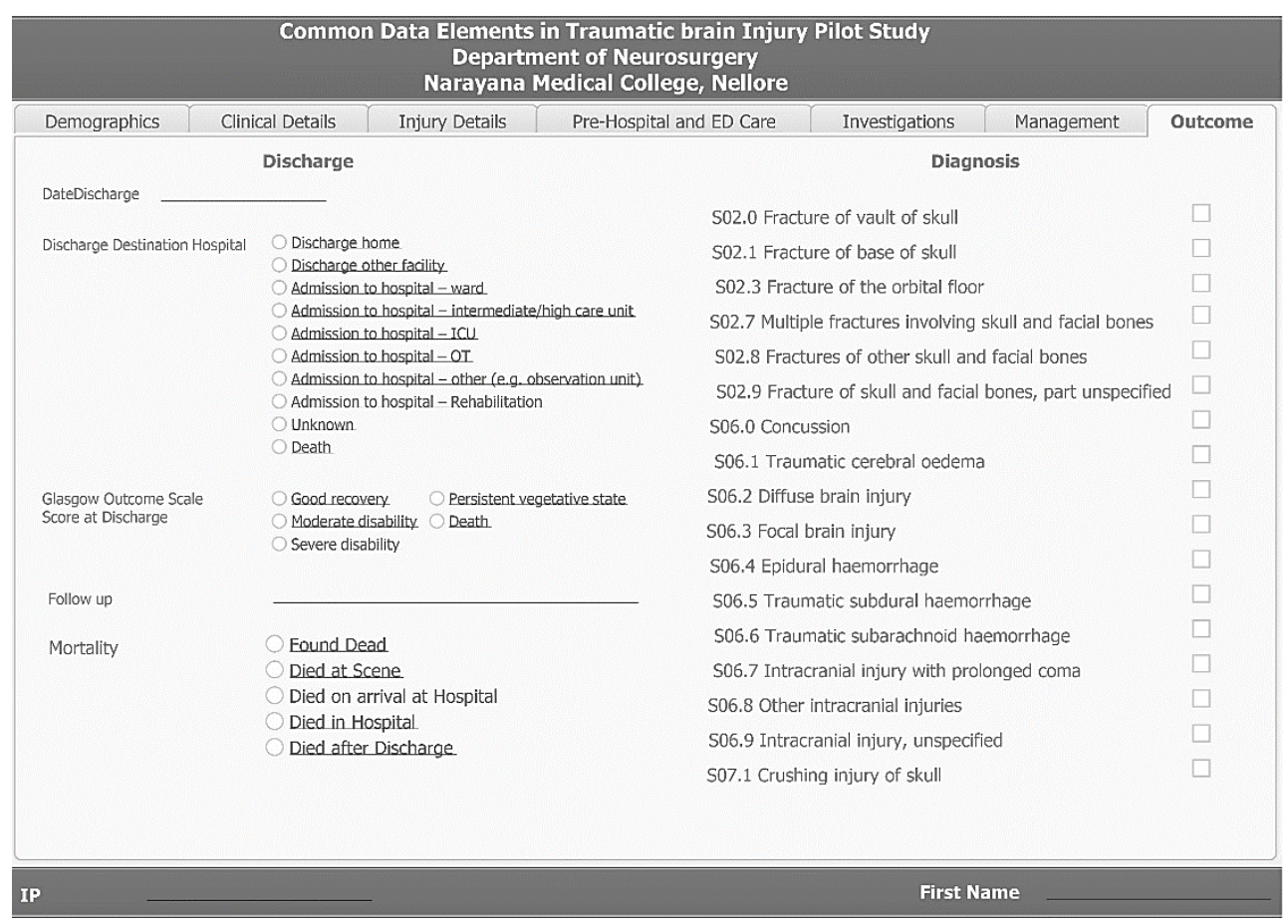




\section{Data variables}

Before establishing a multi-center national data registry it is advisable to development a suitable and concise registry data entry form, database, secure electronic form, availability accessibility to a computer and Internet connection, funded data entry personnel and experienced personnel in trauma injuries in order to continuously maintain and analyze the registry. (1) Many studies have recommended that before starting the data registry it will be useful to define the data set well in advance as it will ensure standardization of variables and will ensure outcome comparison in terms of patient and injury characteristic across many international studies. (2, 19, 24, 30-32) However, the datasets of existing trauma registries frequently lack compatible definitions of common data variables. (33-37) The fundamental principle to develop a data collection form is to avoid a cumbersome forms and the data collection forms should be of simple digital, analogue and 'tick box' design as where possible. (3) It is import to understand that too little data would be having limited value, but too much data could be time-consuming and expensive to collect and administer. (38-42)

\section{Database}

Now a days relational databases are the becoming popular as these are simpler and reliable. 1 The database can be developed as a standalone system or as a web-based system which depend on the ultimate purpose of this database. 1 While converting a paper based data registry to computer based registry many technical considerations (include expert advice from information technologists) needs to be addressed which include selection of hardware, software, operating systems, memory support, and security. (30) It has been found that a simple standalone database is preferred to establish own data registry and a web-based model is preferred to establish a nationwide multi-center trauma registry then a web-based model is preferred. (1) In addition an attractive yet simple user interface will help to simplify the medical terminology and trauma score complexities. (1) To address the issue of an uninterrupted power supply (a condition unattainable in most developing countries) portable computer platforms can be the excellent solution. (43)

\section{Data collection}

Real-time data collection is the ideal but needs extensive funding, the continual presence of a dedicated data collector and almost unlikely to be practical in the prehospital phase (3) particularly in developing countries. A careful prospective planning for collecting data and full co-operation between pre-hospital and in-hospital personnel is mandatory to minimize the possibility of omission or duplication of data. (3) Further data collection can be optimized and simplified if the baseline data can be imported from the hospital electronic medical record system. (19, 30, 44-46) Data security can be ensured by providing username and password, encrypted data transfer which will give access to only authorized technicians and data managers. (1)

\section{Challenges}

The main factors leading to the successful establishment of a multi-center trauma registry are the development of a concise data entry form, development of a user-friendly 
DOI: 10.2478/romneu-2014-0059

secure web-based database system, the availability of a computer and Internet connection in each data collection center, funded data entry personnel well trained in extracting medical data from the medical record and entering it into the computer, and experienced personnel in trauma injuries and data analysis to continuously maintain and analyze the registry. $(1,30)$ Data collection efforts can be hampered by several difficulties, particularly scarcity of funds and lack of adequately trained staff. (30) The cost can be a major determinant for the successful deployment of a data registry system; however as our previous experience has also revealed data trauma registries can be implemented in a cost-effective manner in developing countries. (7, 29, 30) Further as has been described in the literature our study was conducted in a single tertiary-care academic institution with an electronic record keeping system, full-fledged trauma team and roundthe-clock availability of computed tomography (CT) and many other diagnostic modalities and these setting may not reflect the reality of many of the health care facilities in developing countries. (47)

\section{Recommendations}

Implementation of the paper trauma registry can be a useful adjunct before the planned implementation of the electronic data collection system. (9) It is evident that a structured reporting system which is based on a uniform template will permit uniform data collection and future statistics and will facilitate and validate independent or comparative audit of performance and quality of care. $(48,49)$ Although different personnel take part at different stages of trauma care with requirements for data collection, yet there is a potential for the development of a single unifying model which can include a glossary of terms used in the pre-hospital and early hospital phase, and definitions, time points, and intervals. (3) We agree with the recommendations made in 1996, during the 9th ITACCS Symposium in London, where the working group suggested an urgent need for a common terminology and reporting template to facilitate the acquisition, processing, audit and analysis of data which will not only be compatible but comparable also. (3)

\section{Conclusion}

We believe that the present data entry system has the potential to provide a clearer and user friendly descriptive data collection platform based on that a multicenter data entry template can be developed. In the first phase we introduced the paper data collection form, in second phase this data form was converted to an electronic interface. The data collection is continued in the paper form which is now entered into the electronic database for future reference. The next step is to explore the possibility whether it would be feasible to use this as a multi-center traumatic brain injury registry.

\author{
Correspondence \\ Dr. Amit Agrawal \\ Professor of Neurosurgery \\ Department of Neurosurgery \\ Narayana Medical College Hospital \\ Chinthareddypalem \\ Nellore-524003 \\ Andhra Pradesh (India) \\ Email-dramitagrawal@gmail.com \\ dramit_in@yahoo.com \\ Mobile - +91-8096410032
}




\section{References}

1.Shaban S, Eid H, Barka E, Abu-Zidan F. Towards a national trauma registry for the United Arab Emirates. BMC Research Notes 2010;3:187.

2.Ringdal KG, Lossius HM, Jones JM, et al. Collecting core data in severely injured patients using a consensus trauma template: an international multicentre study. Crit Care 2011;15:R237.

3.Dick WF, Baskett PJ. Recommendations for uniform reporting of data following major trauma--the Utstein style. A report of a working party of the International Trauma Anaesthesia and Critical Care Society (ITACCS). Resuscitation 1999;42:81-100.

4.Lossius HM, Langhelle A, Søreide E, et al. Reporting data following major trauma and analysing factors associated with outcome using the new Utstein style recommendations. Resuscitation 2001;50:263-272.

5.WHO | Injury surveillance guidelines [online]. Available at:

http://www.who.int/violence_injury_prevention/publica tions/surveillance/surveillance_guidelines/en/.

6.ICD-10 Version:2010 [online]. Available at:

http://apps.who.int/classifications/icd10/browse/2010/en.

7.Agrawal A, Prasad MV, Kumar SS, Subrahmanyan BV, Harisha PN, Rao GM. Developing a traumatic brain injury registry: lessons learned from difficulties. Romanian Neurosurgery 2014;XXI:307-312.

8.TBI Standards - NINDS Common Data Elements [online]. Available at:

http://www.commondataelements.ninds.nih.gov/TBI.as px\#tab=Data_Standards.

9.Morris SC, Manice N, Nelp T, Tenzin T. Establishing a trauma registry in Bhutan: needs and process. SpringerPlus 2013;2:231.

10.Burkhardt M, Nienaber U, Holstein JH, et al. Trauma registry record linkage: methodological approach to benefit from complementary data using the example of the German Pelvic Injury Register and the TraumaRegister $\mathrm{DGU}((\mathrm{R}))$. BMC medical research methodology 2013;13:30.

11.Teasdale G, Jennett B. Assessment of coma and impaired consciousness. A practical scale. Lancet 1974;2:81-84.

12.Greenspan L, McLellan BA, Greig H. Abbreviated Injury Scale and Injury Severity Score: a scoring chart. The Journal of Trauma 1985;25:60-64.

13.Marshall LF, Marshall SB, Klauber MR, et al. A new classification of head injury based on computerized tomography. Special Supplements 1991;75:S14-S20.
14.Fisher CM, Kistler JP, Davis JM. Relation of cerebral vasospasm to subarachnoid hemorrhage visualized by computerized tomographic scanning. Neurosurgery 1980;6:1-9.

15.Frontera JA, Claassen J, Schmidt JM, et al. Prediction of symptomatic vasospasm after subarachnoid hemorrhage: the modified fisher scale. Neurosurgery 2006;59:21-27; discussion 21-27.

16.Jennett B, Bond M. Assessment of outcome after severe brain damage: a practical scale. The Lancet 1975;305:480-484.

17.PSPP - GNU Project - Free Software Foundation [online]. Available at:

http://www.gnu.org/software/pspp/.

18.Report from the 1988 Trauma Registry Workshop, including recommendations for hospital-based trauma registries. The Journal of trauma 1989;29:827-834.

19.Moore L, Clark DE. The value of trauma registries. Injury 2008;39:686-695.

20.Clark DE, Hahn DR. Hospital trauma registries linked with population-based data. The Journal of trauma 1999;47:448-454.

21.Lucas CE, Buechter KJ, Coscia RL, et al. The effect of trauma program registry on reported mortality rates. The Journal of trauma 2001;51:1122-1126; discussion 1126. 22.Williams JM, Furbee PM, Prescott JE, Paulson DJ. The emergency department log as a simple injury-surveillance tool. Annals of emergency medicine 1995;25:686-691. 23.Agrawal A, Joharapurkar SR, Golhar KB, Shahapurkar VV. Early tracheostomy in severe head injuries at a rural center. J Emerg Trauma Shock 2009;2:56.

24.Rutledge R. The goals, development, and use of trauma registries and trauma data sources in decision making in injury. The Surgical clinics of North America 1995;75:305-326.

25.Agrawal A. Injury surveillance or trauma registry: Need of hour and time to start. The Indian Journal of Neurotrauma 2011;8:37-39.

26.Agrawal A. Fatal road traffic cranio-cerebral injuries: Time to act and need to study. The Indian Journal of Neurotrauma 2012;9:156-157.

27.Agrawal A. A critical appraisal of neurotrauma and neurocritical care perspectives of traumatic brain injuries in Indian scenario. The Indian Journal of Neurotrauma 2013;10:38-42.

28.Agrawal A, Galwankar S, Kapil V, et al. Epidemiology and clinical characteristics of traumatic brain injuries in a rural setting in Maharashtra, India. 2007-2009. International Journal of Critical Illness and Injury Science 
DOI: 10.2478/romneu-2014-0059

2012;2:167-171.

29.Agrawal A, Kakani A, Baisakhiya N, Galwankar S, Dwivedi S, Pal R. Developing traumatic brain injury data bank: Prospective study to understand the pattern of documentation and presentation. The Indian Journal of Neurotrauma 2012;9:87-92.

30.Nwomeh BC, Lowell W, Kable R, Haley K, Ameh EA. History and development of trauma registry: lessons from developed to developing countries. World journal of emergency surgery 2006;1:32.

31.Nathens AB, Brunet FP, Maier RV. Development of trauma systems and effect on outcomes after injury. Lancet 2004;363:1794-1801.

32.Ringdal KG, Coats TJ, Lefering R, et al. The Utstein template for uniform reporting of data following major trauma: a joint revision by SCANTEM, TARN, DGU-TR and RITG. Scandinavian journal of trauma, resuscitation and emergency medicine 2008;16:7.

33.Edwards A, Di Bartolomeo S, Chieregato A, et al. A comparison of European Trauma Registries. The first report from the EuroTARN Group. Resuscitation 2007;75:286-297.

34.Garthe E. Overview of trauma registries in the United States. J AHIMA 1997;68:26, 28-32; quiz 33-24.

35.Mann NC, Guice K, Cassidy L, Wright D, Koury J. Are statewide trauma registries comparable? Reaching for a national trauma dataset. Academic emergency medicine 2006;13:946-953.

36. Owen JL, Bolenbaucher RM, Moore ML. Trauma registry databases: a comparison of data abstraction, interpretation, and entry at two level I trauma centers. The journal of trauma 1999;46:1100.

37.Ringdal KG, Lossius HM. Feasibility of comparing core data from existing trauma registries in scandinavia. Reaching for a Scandinavian major trauma outcome study (MTOS). Scand J Surg 2007;96:325-331.

38.Cameron PA, Finch CF, Gabbe BJ, Collins LJ, Smith KL, McNeil JJ. Developing Australia's first statewide trauma registry: what are the lessons? ANZ journal of surgery 2004;74:424-428.

39.Zafar H, Rehmani R, Raja AJ, Ali A, Ahmed M. Registry based trauma outcome: perspective of a developing country. Emergency medicine journal 2002;19:391-394.

40.Podang J, Singhasivanon P, Podhipak A, Santikarn C,
Sarol JN, Ancheta CA. Primary verification: is the TRISS appropriate for Thailand? The Southeast Asian journal of tropical medicine and public health 2004;35:188-194.

41.Onwudike M, Olaloye OA, Oni OO. Teaching hospital perspective of the quality of trauma care in Lagos, Nigeria. World journal of surgery 2001;25:112-115.

42.Talwar S, Jain S, Porwal R, Laddha BL, Prasad P. Trauma scoring in a developing country. Singapore medical journal 1999;40:386-388.

43.Acosta JA, Hatzigeorgiou C, Smith LS. Developing a trauma registry in a forward deployed military hospital: Preliminary report. The Journal of trauma 2006;61:256260.

44.Schultz CR, Ford HR, Cassidy LD, et al. Development of a hospital-based trauma registry in Haiti: an approach for improving injury surveillance in developing and resource-poor settings. The Journal of trauma 2007;63:1143-1154.

45.Cameron PA, Gabbe BJ, Cooper DJ, Walker T, Judson $\mathrm{R}$, McNeil J. A statewide system of trauma care in Victoria: effect on patient survival. Med J Aust 2008; 189:546-550.

46.Probst C, Paffrath T, Krettek C, Pape H. Comparative Update on Documentation of Trauma in Seven National Registries. European Journal of Trauma 2006;32:357-364. 47.Mehmood A, Razzak JA. Trauma registry-needs and challenges in developing countries. J Pak Med Assoc 2009;59:807-808.

48.Cummins RO, Chamberlain D, Hazinski MF, et al. Recommended guidelines for reviewing, reporting, and conducting research on in-hospital resuscitation: the inhospital 'Utstein style'. A statement for healthcare professionals from the American Heart Association, the European Resuscitation Council, the Heart and Stroke Foundation of Canada, the Australian Resuscitation Council, and the Resuscitation Councils of Southern Africa. Resuscitation 1997;34:151-183.

49.Spaite D, Benoit R, Brown D, et al. Uniform prehospital data elements and definitions: a report from the uniform pre-hospital emergency medical services data conference. Annals of emergency medicine 1995;25:525534 . 